\title{
A Customer Value Creation Framework for Businesses That Generate Revenue with Open Source Software
}

\author{
Aparna Shanker
}

\author{
(6) If you're proactive, you don't have to wait for") \\ circumstances or other people to create perspective \\ expanding experiences. You can consciously create \\ your own. \\ Stephen Covey \\ Author, speaker, consultant, and professor
}

\begin{abstract}
Technology entrepreneurs must create value for customers in order to generate revenue. This article examines the dimensions of customer value creation and provides a framework to help entrepreneurs, managers, and leaders of open source projects create value, with an emphasis on businesses that generate revenue from open source assets. The proposed framework focuses on a firm's pre-emptive value offering (also known as a customer value proposition). This is a firm's offering of the value it seeks to create for a customer, in order to meet his or her requirements.
\end{abstract}

\section{Introduction}

A business model establishes how value is created for customers and a firm's strategy to appropriate returns derived from that value. Typically, a business model identifies: i) the firm's value propositions for customers, partners, and other stakeholders; ii) the processes and resources required to deliver these value propositions; iii) and a profit formula.

In the February issue of the TIM Review, the author described customer value and how it is delivered to customers (Shanker, 2012; timreview.ca/article/525). In this article, the focus is on creating customer value, particularly in the context of businesses that generate revenue using open sources assets.

From a marketing theory perspective, customer value refers to customers' perceptions of what they receive, in return for what they sacrifice (Zeithaml, 1988; tinyurl.com $/ 7 \mathrm{~s} 2 \mathrm{blkp}$ ). There are two aspects to customer value: desired value and perceived value (Woodruff, 1997; tinyurl.com/7lu6wxz). Desired value refers to what a customer desires in a product or service. Perceived value is the benefit a customer believes he or she received from a product after it was purchased. Customer value propositions are formulated by assessing the current market offerings, identifying what customers want, and then developing solutions that meet the market need for a product or service (Anderson et al., 2006; tinyurl.com/7ymgebb). Figure 1 illustrates the customer value creation strategy; it is the author's representation of the extant literature.

When a firm uses a proprietary software business model, value is created by producing specific software that fulfils a customer's need to get a job done or solve a problem. Value may be appropriated using patents and licenses may be required to use the software.

When a firm uses open source software to satisfy customer's needs, value is captured in different ways because the supplier cannot charge for the software. This article reviews current customer value creation strategies and then proposes a value-creation framework for suppliers that rely on open source software to generate revenue. 


\section{A Customer Value Creation Framework for Open Source Software}

\section{Aparna Shanker}

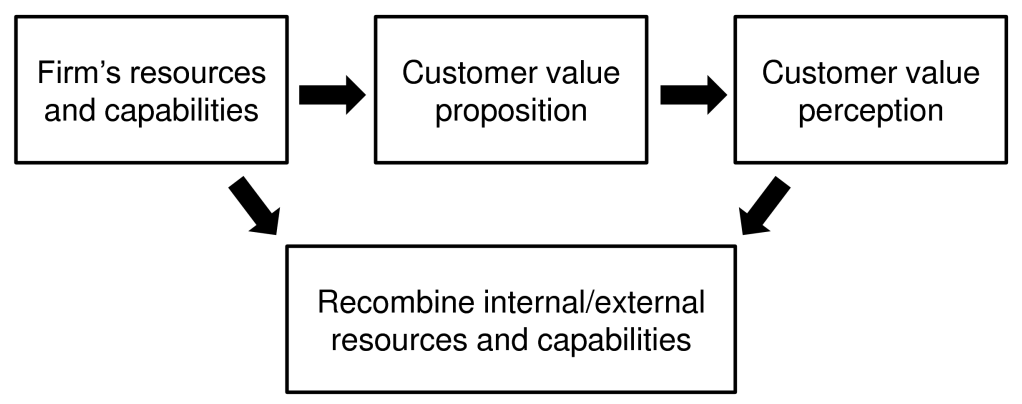

Figure 1. A firm's value creation strategy

\section{Value Creation Frameworks}

To develop a value-creation strategy, a firm must first identify what points of value their potential customers seek. Next, the firm develops a pre-emptive strategy to provide those benefits (O'Cass and Ngo, 2011; tiny url.com/7zqcqpx).

Value-creation strategies focus on the various dimensions along which customers perceive value. Ulaga (2003; tinyurl.com/7pluqjz) identified eight dimensions of value creation in a business-to-business context: product quality, service support, delivery performance, supplier know-how, time-to-market, personal interaction, price, and process costs. While Ulaga focused on relationship value (i.e., manufacturer-supplier relationships), his eight dimensions also apply to an open source context because most consumers or end-customers of commercial open source software are businesses.

Smith and Colgate (2007; tinyurl.com/727r4le) proposed a customer-value creation framework that identifies four main types of value that can be created by organizations:

1. Functional/instrumental value: the attributes of the product itself; the extent to which a product is useful and fulfills a customer's desired goals

2. Experiential/hedonic value: the extent to which a product creates appropriate experiences, feelings, and emotions for the customer

3. Symbolic/expressive value: the extent to which customers attach or associate psychological meaning to a product

4. Cost/sacrifice value: the cost or sacrifice that would be associated with the use of the product
Smith and Colgate proposed their framework as a tool for marketing strategists to develop creative product concepts and recognize new product opportunities. The sources of value identified have to be appropriate and applicable to the context in which they are used. Smith and Colgate's value-creation framework must be adapted to the context of open source software because open source is most attractive to businesses and expert users, such as universities and hobbyist programmers (West, 2007; tinyurl.com/6pwjozm). Some components of the framework might not apply in this context. For example, experiential value is more of an individual assessment than a firm-level assessment. Similarly, symbolic value components such as self-identity, personal meaning, and self-expression, would only apply in cases where the end-customer was an individual user.

O'Cass and Ngo (2011; tinyurl.com/7zqcqpx) assert that a firm's pre-emptive value-creation strategy is comprised of:

1. Performance value: this component is associated with the product attributes and the attributes' performance. This relationship was also noted Woodruff (1997; tinyurl.com/7lu6wxz).

2. Pricing value: this component can refer to the fair price or the value price. The fair price refers to customers believing they are paying a fair price for a product or service; the value price refers to a price that justifies the benefits of purchasing a product.

3. Relationship value: this component refers to the firm's efforts to create and deliver a hassle-free purchase and consumption experience.

4. Co-creation value: this component is added when customers find it beneficial to influence various parts of the business system to co-create or co-produce their own unique purchase and consumption experience. 


\section{A Customer Value Creation Framework for Open Source Software}

\section{Aparna Shanker}

\section{Value Creation in Open Source}

Value-creation frameworks and strategies rely on combining the resources and capabilities of a firm. These resources and capabilities are considered to be valuable, rare, inimitable, and non-substitutable because they provide a sustainable competitive advantage for a firm (Landroguez et al., 2011; tinyurl.com/7mpdtxz).

Firms that produce open source software and related services do not always rely solely on open source software. They usually combine proprietary and open source offerings and employ hybrid business models to deliver greater value to customers (West, 2003: tinyurl.com/6s68jno; Bonaccorsi et al., 2006: tinyurl.com/ 7vnupff). A network of developers (who may be internal and external to the firm), collaborates to produce open source software. Firms that use open source software as one of their resources to create value for customers can use the attributes of open source software to create a competitive advantage. For example, West (2007; tinyurl.com/6pwjozm) recognizes that firms can create value for customers by providing software at lower prices through the use of open source software as one of their resource components.

In addition to a different value creation strategy for producers of open source software, the impact on customer value perceptions also changes with open source. Customers can engage the open source community, influence the direction of the product offering, and increase their interoperability with other vendors by using the same common open source code base. Customer value perceptions in open source software therefore, will differ from proprietary software because customers derive value along additional dimensions that do not apply in proprietary software development models.

The literature on customer value creation in open source software is still very new and few authors have addressed the creation of value in the open source software development model, with the exception of West (2007; tinyurl.com/6pwjozm) and Morgan and Finnegan (2008; tinyurl.com/7jx8gt3).

Some of the key attributes of customer value creation that need to be considered when developing a framework are:

1. Customers perceive value from product attributes, from the consequences of using a product, and from whether they achieve their desired goals (Woodruff, 1997; tinyurl.com/7lu6wxz).
2. For a convincing customer value proposition, a firm needs to identify how value is perceived by customers and then offer those identified points of value in terms of a pre-emptive value offering (O'Cass and Ngo, 2011; tinyurl.com/7zqcqpx).

3. A value creation framework should identify the various types of value (Smith and Colgate, 2007: tinyurl.com/727r4le; O'Cass and Ngo, 2011).

\section{A Proposed Customer-Value Creation Frame- work}

Figure 2 illustrates the author's proposed customervalue creation framework. A firm's value offering is organized into the categories of value creation that apply to a context where one of the firm's resources is open source software. Using the value offering, firms must create a customer value proposition that fulfills customer needs. Figure 2 identifies the characteristics of a customer value proposition that can be used to fulfill customer needs.

\section{Firm's value offering}

1. Functional value: The product attributes that help create value, as identified by Morgan and Finnegan (2008; tinyurl.com/7jx8gt3), are: cost, quality, reliability, security, and performance. These attributes of open source software are features of the product itself; they do not focus on other dimensions of value creation such as attribute consequences and goals. Woodruff's (1997; tinyurl.com/7lu6wxz) customer value hierarchy identifies that customers perceive value not only from the attributes of a product itself but also from the consequences of using a product and the goals achieved by it.

2. Cost/sacrifice value: Customer value perception is often defined as a customer's evaluation of what they get in return for what they give (Zeithaml, 1988; tinyurl.com/7s2blkp). The cost/sacrifice value identifies the customer's perception of whether the value created is worth the cost paid. The cost paid can be in monetary terms, time, effort spend defining requirements, or any other way in which the customer invests in a firm's offering. The commoditization of open source software allows suppliers to provide undifferentiated software at a lower price point, thereby increasing the customer perception of value added (West, 2007; tinyurl.com/6pwjozm).

3. Relationship value: this is refers to the overall customer experience during interactions with the supplier. Value can be added to a relationship along dimensions such as product quality, service support, delivery per- 


\section{A Customer Value Creation Framework for Open Source Software}

\section{Aparna Shanker}

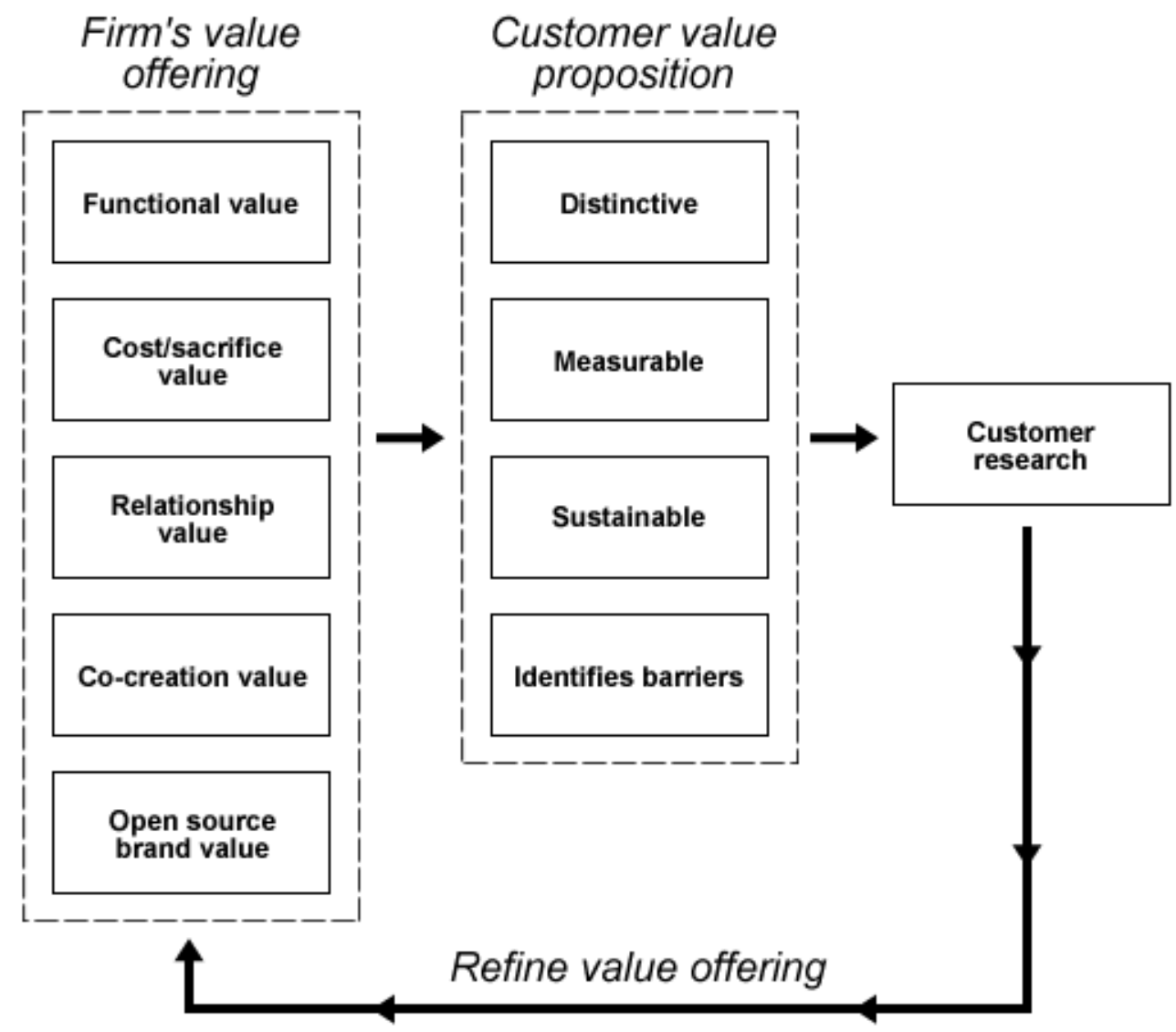

Figure 2. Creating a customer value proposition

formance, supplier know-how, time-to-market, personal interaction, price, and process costs (Ulaga, 2003; tinyurl.com/7pluqjz). Open source software can be combined with complementary assets such as support, customization, integration, or upgrades (West, 2007; tinyurl.com/6pwjozm) to create value for customers. Such value-added offerings encourage customers to develop and maintain a relationship with suppliers to obtain a hassle-free purchase and consumption experience (O'Cass and Ngo, 2011; tinyurl.com/7zqcqpx). Firms that use open source software could also create value for their customers by re-using code and by reducing time to market and production costs; these firms can then use this saved time and money towards enhancing business processes or employee development (Morgan and Finnegan, 2008; tinyurl.com/7jx8gt3).

4. Co-creation value: this is the value perceived in either modifying available source code or defining re- quirements that allow a product to be customized to meet a customer's needs. It is the value customers perceive in having a say in a supplier's manufacturing process (O'Cass and Ngo, 2011; tinyurl.com/7zqcqpx). The nature of open source software allows users to co-create value by actively participating in the development process.

5. Open source brand value: this refers to the value that customers perceive in the open source brand itself. For example, value could be perceived by gaining legitimacy in the open source software community or by creating partnerships with other companies. Customer value creation strategies could change based on the extent to which open source resources are used in an offering (Bonaccorsi et. al., 2006; tinyurl.com/7vnupff). For example, the value in a pure open source offering could be in the supplier's ability to customize without incurring high marginal costs. 


\section{A Customer Value Creation Framework for Open Source Software}

\section{Aparna Shanker}

\section{Customer value proposition}

A customer value proposition can be developed based on the points of value that a firm can create (and that matter to customers). In this respect, a customer value proposition must provide distinctive, measurable, and sustainable value (Anderson et al., 2006; tinyurl.com/ 7ymgebb). A distinctive value proposition is superior to the competitor's offering, a measurable value proposition allows customers to quantify value in monetary terms, and a sustainable value proposition ensures that customers can continue to provide value to customers. A customer value proposition can be constructed by identifying the barriers that limit customers from getting a job done. The four most common barriers identified by Johnson, Christiansen, and Kagermann (2008; tinyurl.com/79gnwyq) are insufficient wealth, access, skill, and time.

\section{Customer research}

To determine what customers want, what job they need to get done, and what barriers they face, a firm needs to conduct customer value research. Based on customer data, firms should then refine their value creation strategy to provide value along the dimensions of value that customers identify as important to them.

\section{Conclusion}

The value creation framework proposed here focuses on the creation of value from an open source business model perspective. The framework can be used in at least three ways. First, it can be used as a guideline for customer value research by manufacturers to assess what points of value matter to customers. Second, it can be used by managers and leaders of open source software projects to determine the points of value that their products and offerings should focus on. Third, managers and leaders can use the customer value di- mensions outlined in the framework to compete along dimensions other than cost.

The level of formal appropriability or control that a firm has over its open source resources impacts the extent to which a firm can capture value from open source software. Therefore, value creation strategies would also be influenced by the degree to which a firm is involved in an open source software project. Future value creation frameworks could take that factor into account because it impacts the resources and capabilities that a firm has at its disposal.

The proposed value creation framework can be refined by conducting customer research to: i) validate the points of value creation identified; ii) determine new dimensions of value creation; and iii) assess the relative importance of each dimension of value from a customer's perspective.

\section{About the Author}

Aparna Shanker is a customer applications engineer with Alcatel-Lucent in Ottawa, where her job focus is on IP networks and the 4G LTE Evolved Packet Core. She is also currently a graduate student in the Technology Innovation Management program at Carleton University. Her research interests include open source businesses and customer value management. She holds an undergraduate degree in Computer Engineering from Queen's University, Kingston.

Citation: Shanker, A. 2012. A Customer Value Creation

Framework for Businesses That Generate Revenue with Open Source Software. Technology Innovation

Management Review. March 2012: 18-22. 